\title{
Identifying the Principal Factors of Business Incubation Processes
}

\author{
Andrés R. Lorán Butrón, D.Eng, Roberto Lorán, Ph.D. \\ ${ }^{1}$ Universidad Ana G. Méndez, Puerto Rico, lorana1@uagm.edu \\ 2Universidad Ana G. Méndez, Puerto Rico, rloran@uagm.edu
}

\begin{abstract}
The common objective of Incubation or Entrepreneurship Programs (IEPs) is to facilitate the entrepreneurial process by meeting the needs of client enterprises and supporting their development. Many studies have been conducted in different contexts to assess the effectiveness of IEPs by relating the incubation process to businesses' performance indicators, particularly in terms of job creation and economic development.

To contribute to overcome the limitations of this approach we adapted the model proposed by Hackett. and Dilts to fit the context of Puerto Rico, particularly in technological aspects. Taking the large set of variables that characterize the processes of the IEPs and using Principal Component Analysis methodology, it is possible to substantially reduce the number of variables needed to capture the principal characteristics of such processes.
\end{abstract}

\section{INTRODUCTION}

In the context of this study, the phrase "Incubation or Entrepreneurship Program" (IEP) refers to a spectrum of services and resources - known as "incubation processes"aimed at facilitating entrepreneurial activities, meeting the needs of a client enterprise, and supporting its performance. Each IEP has its own set of rules and conditions, including the screening process and admission requirements for the client enterprise, hereinafter also referred to variously as the participant, incubatee, tenant, client, or customer. In the IEPs that are the subjects of our study, once an enterprise is admitted to the IEP, it goes through a process of orientation, training, and technical assistance, all aimed at achieving successful development using the facilities and network of the program host organization.

In Puerto Rico, these programs are characterized by being independent and not quite coordinated. Nevertheless, they share essential goals, and the variety of services they offer range from assistance in the ideation of new business models, preparation of business plans, development of work teams, and orientation on capital access to a variety of other more specialized services. Also, as part of their menu, flexible space, shared equipment, and administrative services are included.

To better understand and evaluate the incubation processes, Ref. [6] proposed the first systematically developed and rigorous model. It is based on three multidimensional constructs. In this study we incorporate a new construct, Information Technology (IT), which we validate and implement in the context of Puerto Rico along with the originally proposed Selection Performance (SP), Monitoring and Assistance (MA; which is Monitoring and Business Assistance Intensity renamed), and Resource Allocation (RA; which is Resource Munificence also renamed).

\section{A. Problem Statement}

The economic and social environment in which IEPs operate in Puerto Rico is different from the realities found in other US jurisdictions, as well as in most developing countries. This particular situation makes it difficult for many good practices that are in use in other regional or national contexts to be directly applicable to Puerto Rico. Therefore, here, as a way of understanding the operation of the IEPs, we study the abovementioned constructs of the IEPs' operations: SP, MA, RA, and IT, as illustrated in Fig. 1.1.

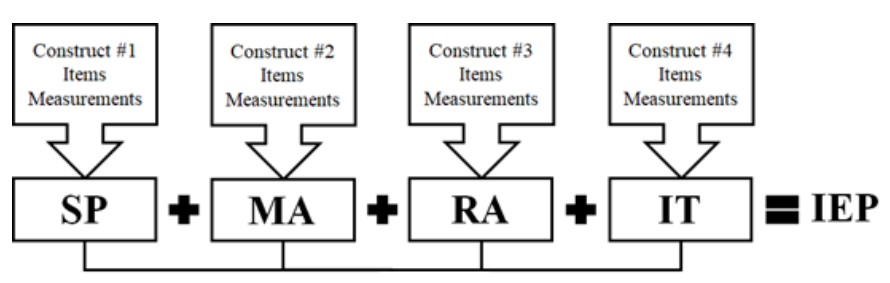

Fig. 1.1 Causality Assessment

From a review of the literature and taking into account the contribution of local specialists, it is possible to identify a large number of attributes or variables that characterize each part of the IEPs' processes identified as a construct (see Fig. 1.1). However, this large number of attributes makes it difficult to interpret in a meaningful way either the data obtained from an appropriate sample or the numerous correlations between pairs of such variables. Therefore, the attributes need to be summarized with a minimum loss of information. Such a summary is possible if for each construct one identifies the subjacent factors that allow variables to be grouped with the most correlations possible for each group. This approach leads us to investigate the principal subjacent factors corresponding to each of the four parts of the IEPs' operations.

As previously stated, the main motivation for carrying out this study is the scarcity of previous studies and analyses that contribute to the planning and management of programs to support entrepreneurship in Puerto Rico. Thus, this work aims to identify the principal underlying factors of IEPs' operations, identify singularities of IEPs and provide a benchmark for IEPs.

\section{B. Key Assumptions and Limitations}

To effect this study, we proposed to solicit opinions from a group of specialists whose responses would aid us in formulating a questionnaire to be answered by the IEPs' former participants. Finally, and importantly, we incorporated a statistical analysis to interpret the data obtained; this analysis,

Digital Object Identifier (DOI):

http://dx.doi.org/10.18687/LACCEI2020.1.1.280

ISBN: 978-958-52071-4-1 ISSN: 2414-6390

$1^{\text {th }}$ LACCEI International Multi-Conference for Engineering, Education, and Technology: "Engineering, Integration, and Alliances for a Sustainable Development" "Hemispheric Cooperation for Competitiveness and Prosperity on a Knowledge-Based Economy", July 27-31, 2020, Virtual Edition. 
we believed, would yield answers aimed at achieving the study's purposes.

This study has two basic assumptions: context and population definition. First, it is limited only to Puerto Rican programs and the data were collected only from former incubation entrepreneurship programs in Puerto Rico. Therefore, the conclusions of this research may not be generalizable to programs in other regions or countries. Second, this study includes business incubation programs as well as similar programs that offer services traditionally attributed to business incubators but that are not known as "incubators" but rather "entrepreneurship programs."

This study has two primary limitations: sample size and sample type. Sample size, due in part to the size of the population under study, limits the impact of the work done. The low participation of former participants of some IEPs and/or types of companies, due mainly to some programs' recent creation, is a hindrance to deepening this investigation so as to draw conclusions specific to IEP categories or types of companies.

\section{LITERATURE REVIEW}

The first systematically developed rigorous model to examine the incubation processes and provide useful data for incubator planning and benchmarking purposes was proposed by Ref. [6] As mentioned above, the model is based on three multi-dimensional constructs. A total of 56 items (questions) are broken down as follows: Selection Performance, with 20 items grouped in 4 dimensions; Monitoring and Business Assistance Intensity, with 14 items grouped in 2 dimensions; and Resource Munificence, with 22 items grouped in 3 dimensions. It was validated with data from 53 incubators from the US. Later, the model was applied in Malaysia [9] with the incorporation of an additional construct, Professional Management Services, which includes marketing and promotion. More recently, it was applied in Nigeria [8] with minor adaptations to the local culture, producing valuable information for the decision-making process of the National Business Incubation Program. When the variables values are obtained from former client enterprises, the model overcomes some of the drawbacks mentioned before, particularly unilateral judgments provided by the programs' management.

As part of her study on the measurement of the performance of business incubators, Ref. [24] highlights the work of Ref. [6] and comments on the relevance of his research, stating that only this work seems to provide validated scales to measure the effectiveness of the business incubators. However, the dimensions and other elements proposed in this work can be adapted to specific contexts by adding, merging and/or eliminating elements. For example, Ref. [8] proposed a total of only 22 items.

\section{A. Selection Performance}

This process is particularly relevant in the case of technological incubators or those oriented to specific sectors in which it is necessary to define specific criteria for the selection of incubatees. In this way, incubators will be able to create more homogeneous groups [10] or have specific resources for the companies on which the program is focused, thus positively impacting the projects' probability of success [1].

Ref. [1] found that most incubators in Europe do not select potential clients on a balanced set of factors but focus on either the characteristics of the market or of the management team [1]. It was found that in the European context, more balanced selection criteria contribute positively to the client enterprise survival rate. In summary, the literature demonstrates that the impact of SP does not always have the same effect in different regions or countries. In our experience, that same practice is widespread in Puerto Rico.

\section{B. Monitoring and Business Assistance}

In general, IEPs offer assistance to the incubated in a variety of formats such as seminars, workshops, consulting, coaching, and mentoring. IEPs' managers and experts in the field recognize the importance of continuous communication between the program management and the incubatees to guarantee that firms make progress in parallel with the milestones developed with them, identify its needs, and provide feedback on the program administration.

Monitoring and evaluation are essential activities that may take place in different ways and formats including formal or informal, one-on-one or team meetings, scheduled presentations, ad-hoc meetings, and panel reviews [15] [17] [19]. Ref. [6] identified two dimensions within the Monitoring and Assistance construct (Comprehensiveness and Quality).

\section{Resource Allocation}

At the beginnings of the industry, it was emphasized in the physical facilities, such as flexible office space, meeting and presentation rooms, space for the coffee, basic telecommunications equipment, etc. Subsequently, numerous authors expanded the IEPs' resources portfolio that should be available to those occupying space in their physical facilities. Typically, they include a variety of resources such as: "administrative assistance, facilities support, business expertise including management, marketing, accounting and finance" [19] as well as a network of interactive community of entrepreneurs, academics and business leaders [19] [12] [18] [3] [14].

The resources of the business incubators have been studied from many different perspectives, such as networking capabilities and cooperation practices [2] and firm's knowledge acquisition methods [22]. Ref. [13] studied the value-added contributions - particularly to technology-based start-ups - of the incubator's connection to a university.

\section{Information Technology}

Information technology support and infrastructure positively and significantly influence the early development of firms and contribute to increasing graduation performance in China's three-tier city-government and university-sponsored technology-based incubators [25]. "When developing highly innovative products or services, incubator firms are most likely 
to receive support from strong and close ties such as professors at a university" [20]. In the literature, one sees that proximity to the sources of scientific and technological knowledge, such as academic institutions, and research centers is vital for a firm's development. Entrepreneurs greatly value university networks as an important element within their relationship portfolio and as an effective means of using technological developments to achieve a competitive advantage [11].

The definition of Information Technology (IT) adopted for this study encompass support for mobile devices and server applications, data communications and network security needs, software, and cloud computing solutions selection processes, access to a network of high-level experts, and availability of modern technical technological infrastructure.

\section{RESEARCH METHODOLOGY}

In our study, we update Hackett and Dilts model [5] [6] to be applied in Puerto Rico. Fig. 3.1 summarizes the study's methodology by illustrating the sequence of the principal activities and their outcomes.

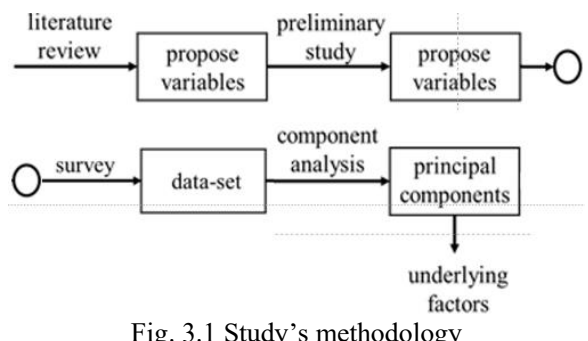

\section{A. Constructs, Dimensions, and Items}

In the context of this research, a construct is an integral part of IEP operations that although it cannot be directly measured, can be assessed indirectly through a number of observable variables in biunivocal correspondence with the items of the questionnaire. These variables are grouped in dimensions that reliably reflect interrelated aspects of the processes.

A preliminary study was carried out to determine the relevance of the constructs as well as the dimensions, the items, and their phrasing. In the following sections the constructs, dimensions, and items are thoroughly described.

1) Selection Performance: Selection Performance (SP) is defined as the construct referring to the decision process concerning which ventures to accept for entry and which to reject. SP comprises 13 observable variables (items) that correspond to the different characteristics that can be taken into account in this construct. These variables are grouped in four dimensions as they relate to each of the following aspects: managerial, market, product/service and financial. The variables and dimensions describing the SP construct are shown in Table 3.1.
TABLE 3.1

SELECTION PERFORMANCE (SP) DIMENSIONS AND ITEMS

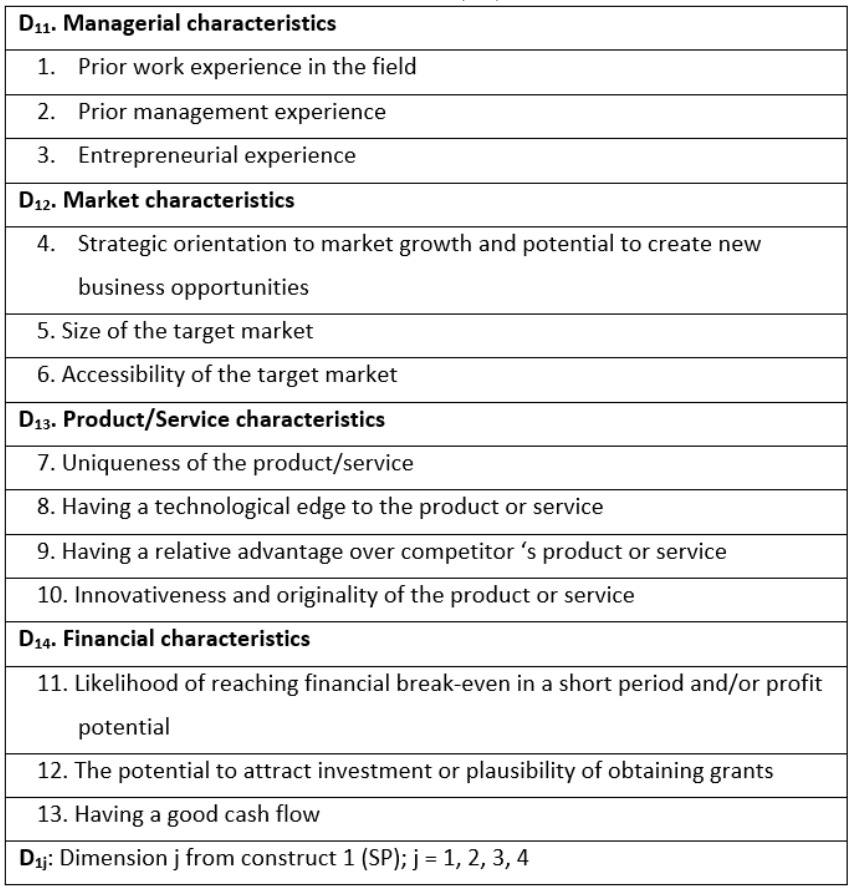

2) Monitoring and Assistance: As defined by Ref. [6] the MA construct refers to the processes by which the IEP observes, advises, and assists incubatees during their incubation, including helping them to learn from their own failures in order to avoid future losses. MA comprises seven observable variables (items) that correspond to the different components that can be part of this process. These variables are grouped in two dimensions as they relate to time or to comprehensiveness and quality. The variables and dimensions describing the MA construct are shown in Table 3.2.

TABLE 3.2

MONITORING AND ASSISTANCE (MA) DIMENSIONS AND ITEMS

\begin{tabular}{|l|}
\hline D21.Time \\
\hline $\begin{array}{l}\text { 14. On average, our enterprise received appropriate time in assistance from the } \\
\text { incubation program staff. }\end{array}$ \\
\hline $\begin{array}{l}\text { 15. On average, our enterprise spent appropriate time interacting with other } \\
\text { participants in the incubation program }\end{array}$ \\
through the interactions with the incubation program staff and other \\
incubates \\
\hline D22. Comprehensiveness \& Quality \\
\hline $\begin{array}{l}\text { 17. Our enterprise received business planning and administrative assistance from } \\
\text { the incubation program }\end{array}$ \\
\hline $\begin{array}{l}\text { 18. Our enterprise received production/operation-related advice from the } \\
\text { incubation program }\end{array}$ \\
\hline $\begin{array}{l}\text { 19. The program ensured the quality of its offerings by regularly reviewing them } \\
\text { and actively seeking improvements }\end{array}$ \\
\hline 20. The other participants contributed to improve our business strategies \\
\hline D2j: Dimension $\mathrm{j}$ of the construct 2 (MA); $\mathrm{j}=1,2$ \\
\hline
\end{tabular}


3) Resource Allocation: This construct refers to the availability, quality, and utilization of resources inherent to the incubation process. RA comprises 14 observable variables (items) that correspond to the different aspects of this process. These variables are grouped in three dimensions as they relate to resource availability, comprehensiveness and quality, and utilization. The variables and dimensions describing the RA construct are shown in Table 3.3.

TABLE 3.3

RESOURCE ALLOCATION (RA) DiMENSIONS AND ITEMS

\begin{tabular}{|l|}
\hline D31. Resource Availability \\
\hline 21. Access to administrative support services \\
\hline 22. Access to professional services \\
\hline 23. Access to consultants \\
\hline 24. Access to funding and grants \\
\hline 25. Access to local university contacts \\
\hline 26. Access to intellectual property advice \\
\hline 27. Access to technology labs \\
\hline D32. Comprehensiveness \& Quality \\
\hline 28. Our company was offered viable solutions to meet space needs \\
\hline 29. Our reputation is enhanced because of our association with the program \\
\hline 30. The entrepreneurial program environment was nurturing and pleasant \\
\hline $\begin{array}{l}\text { 31. We received useful training and coaching from the program in a way that was } \\
\text { easy to understand }\end{array}$ \\
\hline D33. Utilization \\
\hline $\begin{array}{l}\text { 32. Our enterprise made full use of the administrative services offered by the } \\
\text { program }\end{array}$ \\
\hline 33. Our enterprise utilized advice obtained from the program \\
\hline 34. Our enterprise utilized the knowledge obtained from other participants \\
\hline $\begin{array}{l}\text { 35. We maximized our opportunities from the introduction to the incubation } \\
\text { program network contacts }\end{array}$ \\
\hline D3j: Dimension j of the construct 3 (RA); $=1,2,3$ \\
\hline
\end{tabular}

4) Information Technology: To further tailor the modeling of the enterprise performance, an additional construct was added in the research design, to include targeted information technology infrastructure and services. IT comprises nine observable variables (items) that correspond to the different aspects of this process. These variables are grouped in two dimensions as they relate to resource availability and/or utilization. The variables and dimensions describing the IT construct are shown in Table 3.4.

TABLE 3.4

INFORMATION TECHNOLOGY (IT) DIMENSIONS AND ITEMS

\begin{tabular}{|l|}
\hline D41. Resource Availability \\
\hline 36. Data and voice communications \\
\hline 37. General administrative applications \\
\hline 38. Specialized software \\
\hline 39. Advice for needs analysis and design \\
\hline 40. System management and programming specialists \\
\hline D42. Utilization \\
\hline $\begin{array}{l}\text { 41. Our enterprise made use of data and voice communication services offered by } \\
\text { the program }\end{array}$ \\
\hline $\begin{array}{l}\text { 42. Our enterprise utilized general administrative applications made available by } \\
\text { the program }\end{array}$ \\
\hline 43. Our enterprise made use of specialized software offered by the program \\
\hline $\begin{array}{l}\text { 44. Our enterprise received system management and programming services } \\
\text { available at the program }\end{array}$ \\
\hline D4j: Dimension $\mathrm{j}$ of the construct 4 (IT); $\mathrm{j}=1,2$ \\
\hline
\end{tabular}

\section{B. Measuring the Variables}

Evaluation of the variables is accomplished by means of a sentence (a question or a statement) instructing respondents to select a point in a seven-point Liker-type scale. The scale is used to gauge to what degree the respondent agrees with the sentence. Each item connects to the corresponding dimension as shown in Table 3.5.

TABLE 3.5

EVALUATING WITH GUIDING SENTENCES

\begin{tabular}{|l|c|}
\hline \multicolumn{1}{|c|}{ Sentence } & Items \\
\hline $\begin{array}{l}\text { To what extent do you perceive the following managerial characteristics to } \\
\text { be important in the selection process into the incubation program? }\end{array}$ & I1-I3 \\
\hline $\begin{array}{l}\text { To what extent do you perceive the following market characteristics to be } \\
\text { important in the selection process into the incubation program? }\end{array}$ & I4-I6 \\
\hline $\begin{array}{l}\text { To what extent do you perceive the following product/service characteristics } \\
\text { to be important in the selection process into the incubation program? }\end{array}$ & I7-I10 \\
\hline $\begin{array}{l}\text { To what extent do you perceive the following financial characteristics to be } \\
\text { important in the selection process into the incubation program? }\end{array}$ & I11-I13 \\
\hline $\begin{array}{l}\text { To what extent do you agree time to be an important part of monitoring and } \\
\text { business assistance? }\end{array}$ & I14-I16 \\
\hline $\begin{array}{l}\text { To what extent do you agree comprehensiveness \& quality to be an } \\
\text { important part of monitoring and business assistance? }\end{array}$ & I17-I20 \\
\hline $\begin{array}{l}\text { The incubation program excels at making the following resources available } \\
\text { to the participants: }\end{array}$ & I21-27 \\
\hline $\begin{array}{l}\text { Please rate the quality of the following characteristics of the incubation } \\
\text { program: }\end{array}$ & I28-I31 \\
\hline $\begin{array}{l}\text { Please rate your enterprise's utilization of the following resources provided } \\
\text { at the incubation program: }\end{array}$ & I32-I35 \\
\hline $\begin{array}{l}\text { Our program excels at making information technology resources available } \\
\text { for the participants: }\end{array}$ & I37-I40 \\
\hline $\begin{array}{l}\text { Please rate your enterprise 's utilization of the following information } \\
\text { technology resources provided at the incubation program: }\end{array}$ & I41-I44 \\
\hline
\end{tabular}

Adapted and translated from Ref. [6] and Ref. [9]

\section{Summarizing Observed Variables}

Data analyses was undertaken using Principal Component Analysis (PCA). PCA is a multivariate statistical procedure that allows researchers to summarize the information content in likely correlated observed variables (items) by means of a smaller set of new unobserved linearly uncorrelated variables called principal components which can be more easily visualized and analyzed.

Although there are other methodologies available for a similar purpose, we follow Ref. [7] who suggest that PCA is the most appropriate methodology when it comes to exploratory research or when the researcher wants to condense a series of variables. PCA "uses the correlations among the variables to develop a small set of components that empirically summarizes the correlations among the variables" [23]. PCA is based on the number of variables and the magnitude of the factor loadings and the measured variables are themselves of interest, rather than being some hypothetical latent construct [16]. Further, Ref. 
[4] determined that the solutions generated from PCA differ little from those obtained with other methods of analysis.

PCA allows the researcher to find linear combinations of weighted observed variables to maximize the variance extracted from the variables in a specific construct. Once a component is identified, the variance is extracted from the variables, and another component is searched, and so on.

For $\mathrm{i}=1,2, \ldots, \mathrm{n}$ observations PCA transforms $\mathrm{j}=1,2, \ldots$, $\mathrm{p}$ observed variables to $\mathrm{k}=1,2, \ldots, \mathrm{p}$ new uncorrelated principal components (variables) $\left(\mathrm{Y}_{1}, \mathrm{Y}_{2}, \ldots, \mathrm{Y}_{\mathrm{p}}\right)$

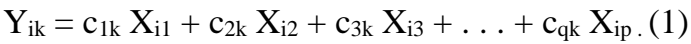

$\mathrm{Y}_{\mathrm{ik}}=$ value for component $\mathrm{k}$ for observation $\mathrm{i}$.

$c_{j k}=$ coefficients that weight how much each item $j$ contributes to the linear combination forming component $\mathrm{k}$.

$X_{\text {ir }}=$ values of the observation i for observed variable (item) $r$.

The weights by which each observed variable should be multiplied to get the component are referred as component loadings. After collecting and preparing the data, PCA is performed in the following four stages: (1) Assumptions verification, (2) Extraction, (3) Rotation, and (4) Interpretation.

1) Assumptions Verification: To produce a reliable result, a sample size larger than 100 , or 5 times the number of variables, is recommended [21]. In addition, due to the software application with which the data is collected, it is guaranteed that there are no missing data or outliers. The following four assumptions need to be verified to produce a valid result: sufficient correlations, multicollinearity, Kaiser-Meyer-Olkin (KMO) measure of sampling adequacy and Barlett's test.

To justify the application of this methodology, the observed variables must have relevant correlation coefficients. That is, they cannot all be low or equal, because this would imply that there is no underlying structure allowing the variables to be grouped together. If this were the case, there are other methodological approaches available. Ref. [7] recommend a visual inspection of the correlations matrix to determine whether there are a "small" number of elements greater than .30 [7].

PCA is based on Pearson correlation coefficients, and thus two or more of the variables need to be moderately or highly correlated. It is suggested that a few possible relationships between variables be selected and tested visually using scatterplots. KMO Measure of Sampling Adequacy and The Bartlett test of sphericity are ways to verify the suitability of the data for a PCA.

2) Principal Components: During a PCA there are as many components as there are observed variables, but not all of them will be equally relevant and an extracting method will be used. In this study, five methods or criteria are applied when extracting components: (1) Item loadings, (2) Kaiser criteria, (3) Total variance, (4) Scree plot test, and (5) Parallel analysis (PA).

Rotation is a procedure normally used after extraction to interpret and clarify the nature of the components. We choose to apply Varimax, which is the rotation method most frequently applied in analyses of this type. The final determination of the components to be extracted is made by running the analysis and extracting components and seeing the number of components producing the most interpretable results.

\section{ANALYSIS AND RESULTS}

The initial version of the questionnaire proposed by the researchers was improved using the results of the preliminary study and an examination of relevant literature. Some participants in the preliminary study suggested merging closely related items to avoid misinterpretations and vagueness in the responses.

Some recommendations were focused on the wording of the items to make the questionnaire more understandable and relevant to the context. The island's linguistic peculiarities were the basis for some changes recommended to the lexicon. Updates to the survey questionnaire were made to reflect the recommendations by the participants in the preliminary study; it was then published on the web and for the data collection. This was followed by the statistical procedures to validate the previously defined dimensions.

\section{A. Data Collection}

The data were generated from the questionnaire responses provided by 103 former IEP participants. Their highest academic degree was distributed as follows: $42 \%$ baccalaureate, $38 \%$ masters, $17 \%$ doctorate, and $1 \%$ high school. The duration of their respective incubation or entrepreneurship programs was less than one year for $60 \%$ of them and longer than one year for $40 \%$. Their respective age groups were as follows: $15.53 \%$ were 18 to 29 years old; $37.86 \%$ were 30 to $39 ; 27.18 \%$ were 40 to 49 years; $12.62 \%$ were 50 to 59; and $6.80 \%$ were older than 60 years. In terms of leaving their respective programs: $50 \%$ left less than one year ago and $50 \%$ more than one year ago.

\section{B. Principal Underlying Factors}

Prior to initiating the extraction process, visual inspection of the data set was performed and verified. Thirteen out of 116 responses with incomplete data were eliminated and no outliers were identified, so the data set was ready to be handled using SPSS. Multicollinearity between variables was verified by visually inspecting scatterplots showing the relationships between some pairs of variables

The extraction process was performed in separate runs for each of the four constructs. The correlation coefficient matrices were visually inspected, and it was found that all the coefficients were greater than .30 , thus justifying the application of PCA methodology.

Table 4.1 shows in four separate rows the results of KMO and Bartlett tests to verify the suitability of the data for structure detection for each of the constructs. The values of the KMO statistics are $.750, .703, .785$, and .710 , indicating that a component analysis may be performed for each of the constructs. The significance level (Sig) of the Bartlett's test in 
all cases is $\mathrm{Sig}<.05$, indicating that a component analysis may be useful.

TABLE 4.1

KMO AND BARLETT'S TEST FOR THE DATA SUBSETS

\begin{tabular}{|c|c|c|c|}
\hline Construct & KMO & \multicolumn{2}{|l|}{ Barlett's Test } \\
\hline \multirow{3}{*}{$\begin{array}{c}\text { Selection } \\
\text { Performance }\end{array}$} & \multirow{3}{*}{0.75} & Approx. Chi-Square & 956.18 \\
\hline & & df & 78 \\
\hline & & Sig. & $3.2 * 10^{-151}$ \\
\hline \multirow{3}{*}{$\begin{array}{l}\text { Monitoring and } \\
\text { Assistance }\end{array}$} & \multirow{3}{*}{0.703} & Approx. Chi-Square & 459.00 \\
\hline & & df & 21 \\
\hline & & Sig. & $5.3 * 10^{-84}$ \\
\hline \multirow{3}{*}{$\begin{array}{l}\text { Resource } \\
\text { Allocation }\end{array}$} & \multirow{3}{*}{0.785} & Approx. Chi-Square & 1294.89 \\
\hline & & \begin{tabular}{l|}
$\mathrm{df}$ \\
\end{tabular} & 105 \\
\hline & & Sig. & $3.8 * 10^{-204}$ \\
\hline \multirow{3}{*}{$\begin{array}{l}\text { Information } \\
\text { Technology }\end{array}$} & \multirow{3}{*}{0.71} & Approx. Chi-Square & 955.05 \\
\hline & & \begin{tabular}{|l|}
$\mathrm{df}$ \\
\end{tabular} & 36 \\
\hline & & Sig. & $4.2 * 10^{-177}$ \\
\hline
\end{tabular}

Once it had been verified that all the requisites for applying PCA were fulfilled, we proceeded with the extraction process. As explained above, we applied five criteria to extract the components: (1) Item loadings, (2) Kaiser criteria, (3) Total variance, (4) Scree plot test, and (5) Parallel analysis.

Each construct's run produced the table "Total Variance Explained". To decide how many components to extract, the Kaiser and total variance criteria were applied. We kept the components with eigenvalue greater than 1 comprising at least $60 \%$ of the variance, discarding the others that resulted as follows: 3 components for SP, 2 components for MA, 3 components for RA, and 2 components for IT.

Along the "Total Variance Explained" table, each run produced a corresponding scree plot. In all cases the components kept were those over the steep slope while those over the shallow part of the graphic were discarded, confirming thus the previous findings of the Kaiser criteria. The next step was the Varimax rotation, which was performed in separate runs, one for each construct.

Table 4.2 summarizes for each construct (first column) the extracted components, obtained in separate SPSS runs, the corresponding observed variables (items per component column) with their respective loadings (below each of the item), and percent of variance and cumulative percent of variance. Note that to make the results easier to interpret non-meaningful observed variables loading below .4 were removed, resulting also in the elimination of cross-loads.

Using the software application Montecarlo PCA for Parallel Analysis, eigenvalues were obtained from randomly produced data. The nonexistence of spurious components is confirmed, and in consequence, all the extracted components will be retained.
TABLE 4.2

EXTRACTED COMPONENTS, OBSERVED VARIABLES LOADINGS AND VARIANCE

\begin{tabular}{|c|c|c|c|c|c|c|c|c|c|c|}
\hline Construct & \multirow{3}{*}{\begin{tabular}{|c|} 
Component \\
$\mathrm{C}_{11}$ \\
\end{tabular}} & \multicolumn{7}{|c|}{ Items per component } & \multirow{3}{*}{\begin{tabular}{|c|}
$\begin{array}{c}\% \text { of } \\
\text { Variance }\end{array}$ \\
$41.3 \%$ \\
\end{tabular}} & \multirow{3}{*}{\begin{tabular}{|c|}
$\begin{array}{c}\text { Cumulative } \\
\%\end{array}$ \\
$41.3 \%$ \\
\end{tabular}} \\
\hline \multirow{6}{*}{$\begin{array}{c}\text { Selection } \\
\text { Performance }\end{array}$} & & I5 & I6 & I7 & I8 & I9 & I10 & & & \\
\hline & & 0.761 & 0.736 & 0.785 & 0.765 & 0.897 & 0.799 & & & \\
\hline & \multirow{2}{*}{$\mathrm{C}_{12}$} & I1 & I2 & I3 & I4 & & & & \multirow{2}{*}{$17.6 \%$} & \multirow{2}{*}{$58.9 \%$} \\
\hline & & 0.909 & 0.915 & 0.562 & 0.706 & & & & & \\
\hline & \multirow{2}{*}{$\mathrm{C}_{13}$} & I11 & I12 & I13 & & & & & \multirow{2}{*}{$12.7 \%$} & \multirow{2}{*}{$71.5 \%$} \\
\hline & & 0.931 & 0.784 & 0.833 & & & & & & \\
\hline \multirow{4}{*}{$\begin{array}{c}\text { Monitoring } \\
\text { and } \\
\text { Assistance }\end{array}$} & \multirow{2}{*}{$\mathrm{C}_{21}$} & I14 & $\mathrm{I} 15$ & I16 & I17 & & & & \multirow{2}{*}{$55.9 \%$} & \multirow{2}{*}{$55.9 \%$} \\
\hline & & 0.896 & 0.667 & 0.685 & 0.829 & & & & & \\
\hline & \multirow{2}{*}{$\mathrm{C}_{22}$} & I18 & I19 & $\mathrm{I} 20$ & & & & & \multirow{2}{*}{$16.3 \%$} & \multirow{2}{*}{$72.2 \%$} \\
\hline & & 0.932 & 0.852 & 0.793 & & & & & & \\
\hline \multirow{6}{*}{$\begin{array}{l}\text { Resource } \\
\text { Allocation }\end{array}$} & \multirow{2}{*}{$\mathrm{C}_{31}$} & I25 & $\mathrm{I} 26$ & I 27 & $\mathrm{I} 28$ & I29 & $\mathrm{I} 30$ & $\mathrm{I} 31$ & \multirow{2}{*}{$42.2 \%$} & \multirow{2}{*}{$42.2 \%$} \\
\hline & & 0.857 & 0.839 & 0.751 & 0.858 & 0.913 & 0.87 & 0.524 & & \\
\hline & \multirow{2}{*}{$\mathrm{C}_{32}$} & $\mathrm{I} 32$ & $\mathrm{I} 33$ & $\mathrm{I} 34$ & $\mathrm{I} 35$ & & & & \multirow{2}{*}{$19.6 \%$} & \multirow{2}{*}{$61.8 \%$} \\
\hline & & 0.924 & 0.803 & 0.911 & 0.851 & & & & & \\
\hline & \multirow{2}{*}{$\mathrm{C}_{33}$} & $\mathrm{I} 21$ & $\mathrm{I} 22$ & I 23 & I 24 & & & & \multirow{2}{*}{$11.2 \%$} & \multirow{2}{*}{$73.0 \%$} \\
\hline & & \begin{tabular}{|l|}
0.864 \\
\end{tabular} & 0.838 & 0.626 & 0.804 & & & & & \\
\hline \multirow{4}{*}{$\begin{array}{l}\text { Information } \\
\text { Technology }\end{array}$} & \multirow{2}{*}{$\mathrm{C}_{41}$} & I40 & I41 & I42 & I I43 & I44 & & & \multirow{2}{*}{$59.2 \%$} & \multirow{2}{*}{$59.2 \%$} \\
\hline & & \begin{tabular}{|l|}
0.885 \\
\end{tabular} & 0.545 & 0.896 & 0.915 & 0.93 & & & & \\
\hline & $C_{0}$ & I 36 & I37 & I 38 & I 39 & & & & $168 \%$ & $760 \%$ \\
\hline & $C_{42}$ & 0.915 & 0.91 & 0.644 & 0.712 & & & & $10.0 \%$ & $10.0 \%$ \\
\hline
\end{tabular}

As a result of the application of the PCA methodology, as described above, the underlying factors of IEPs' operations were identified, Table 4.3 includes proposed component labels and their descriptions. These results coincide partially with the classification of the observed variables (dimensions) proposed in section 3.1 .

TABLE 4.3

FACTORS OF IEP's OPERATIONS

\begin{tabular}{|l|l|l|}
\hline \multicolumn{2}{|c|}{ Component label } & \multicolumn{1}{c|}{ Component explanation } \\
\hline C11 & Product and market & $\begin{array}{l}\text { Characteristics of the product/service and } \\
\text { connection to the target market }\end{array}$ \\
\hline C12 & $\begin{array}{l}\text { Proponent experience and } \\
\text { strategic orientation }\end{array}$ & $\begin{array}{l}\text { Proponent relevant experience and project } \\
\text { orientation to market growth }\end{array}$ \\
\hline C13 & Financial aspects & $\begin{array}{l}\text { Likelihood of economic success and attractiveness } \\
\text { to funding sources }\end{array}$ \\
\hline C21 & $\begin{array}{l}\text { Business and planning } \\
\text { assistance intensity }\end{array}$ & $\begin{array}{l}\text { Business and planning assistance received from } \\
\text { interactions with staff and other participants }\end{array}$ \\
\hline C22 & $\begin{array}{l}\text { Operation related } \\
\text { services }\end{array}$ & $\begin{array}{l}\text { Operational related services received from } \\
\text { interactions and their continuous improvement }\end{array}$ \\
\hline C31 & $\begin{array}{l}\text { Networking and support } \\
\text { effectiveness }\end{array}$ & $\begin{array}{l}\text { Effective access to networking and support by } \\
\text { provision of space, labs, and specialists }\end{array}$ \\
\hline C32 & Resources utilization & $\begin{array}{l}\text { Utilization of available resources including space, } \\
\text { network and support from staff and participants }\end{array}$ \\
\hline C33 & $\begin{array}{l}\text { Professional support and } \\
\text { funding }\end{array}$ & $\begin{array}{l}\text { Availability of administrative support, professional } \\
\text { services, consultancy and funding opportunities }\end{array}$ \\
\hline C41 & $\begin{array}{l}\text { IT resources utilization } \\
\text { and programing }\end{array}$ & $\begin{array}{l}\text { Information resources utilization and availability of } \\
\text { programing services }\end{array}$ \\
\hline C42 & IT resources availability & $\begin{array}{l}\text { Availability of IT resources including networks, } \\
\text { computing applications, and design services }\end{array}$ \\
\hline
\end{tabular}

Comparing the components extracted by PCA with the dimensions of the theoretical model, we found some differences in the grouping of the variables. Table 4.4 illustrates these differences for each construct. On the lines labeled D the shadowed ovals indicate how the items were grouped under the proposed dimensions and on the lines labeled $\mathrm{C}$ the shadowed ovals indicate how the items were grouped under each construct as a result of the PCA. The main change in the SP construct is 
that the dimensions "Market Characteristics" and "Product/Service Characteristics" were grouped in the component labeled "Product and market". The only change in MA is that I17 moved from the Comprehension and Quality dimension to form the component labeled "Planning assistance intensity". The only change in the RA construct is that I25, I26, and 127 joined the Quality dimension to form the component label "Networking and support effectiveness". The only change in IT is that I40 moved from the Resource Availability dimension to form the component label "IT resources utilization and programing".

TABLE 4.4

ITEMS GROUPING IN DIMENSIONS AND COMPONENTS

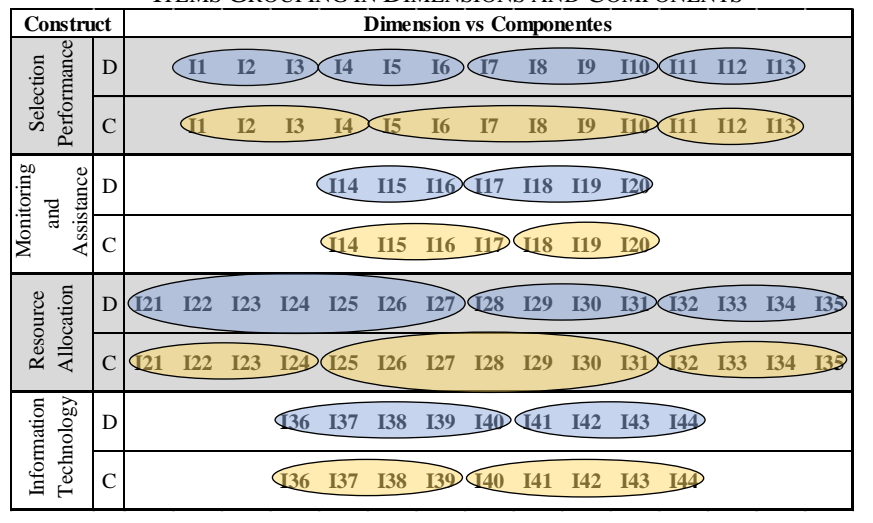

V. CONCLUSIONS AND RECOMMENDATIONS

This is the first time that a rigorous investigation to explore the structure and characteristics of IEPs' operations in Puerto Rico is performed. The research produced an integral vision of the subjacent factors of IEPs' operations. This study's approach is of greater interest because it offers a broader theoretical framework applicable to a larger number of organizations. It is also the first time that a construct in addition to those proposed by Ref. [6] - that is, information technologies - has been included.

The valuable results of this study are the consequence of the rigorous standards adopted in conducting the research and analysis, as well as the strong support received from the participants in the study, the management of the IEPs, and the organizations that fund and host the programs. The study's availability, in addition to the considerable amount of data produced in the different stages of the project, present several additional research possibilities.

As a continuation of this research, this model may serve as the basis to predict the outcomes of enterprise performance (EP), to evaluate the importance of the individual predictors, and to assess interaction effects. The extracted components of the PCA may be used as predictor variables, while the variable EP remains as the dependent variable.

\section{REFERENCES}

[1] Aerts, K., Matthyssens, P. and Vandenbempt, K. (2007). Critical role and screening practices of European business incubators. Technovation, Vol. 27: pp. 254-267.
[2] Bollingtoft, A. and Ulhoi, J. P. (2005). The networked business incubator-leveraging entrepreneurial agency? Journal of Business Venturing, 20(2), pp. 265-290.

[3] Campbell, C. J., (1989). Change Agents in the New Economy: Business Incubators and Economic Development, Minneapolis, MN: University of Minnesota.

[4] Field, A. (2009). Discovering Statistics Using SPSS, 3rd ed., SAGE Publications.

[5] Hackett, S. M. and Dilts, D. M. (2004). A systematic review of business incubation research. Journal of Technology Transfer, 29(1), pp. 55-82.

[6] Hackett, S. M. and Dilts, D. M. (2007). Inside the Black Box of Business Incubation: Study B-scale Assessment, Model Refinement, and Incubation Outcomes. Journal of Technology Transfer, Vol 33, pp. 439-471.

[7] Hair, J. F., Black, W.C., Babin, B. J. and Anderson, R. E. (2018). Multivariate Data Analysis: A Global Perspective. 8th Edition, CENGAGE Learning, Cheriton House, UK.

[8] Iyortsuun, A. S. (2017). An empirical analysis of the effect of business incubation process on enterprise performance in Nigeria. Journal of Small Business \& Entrepreneurship, 29(6), pp. 433-459.

[9] Khalid, F. A., Gilbert, D. and Huq, A. (2012). Investigating the Underlying Components in Business Incubation Process in Malaysian ICT Incubators. Asian Journal of Social Sciences and Humanities, Vol. 1 No. 1, pp. 88-102.

[10] Lambing, P. A. and Kuehl, C. R. (2003). Entrepreneurship. Upper Saddle River. Prentice Hall.

[11] McAdam, M. and McAdam, R. (2006). The networked incubator: The role and operation of entrepreneurial networking with the university science park incubator (USI). International. Journal of Entrepreneurship and Innovation, 7(2), pp. 87-98.

[12] Merrifield, B. (1987). New business incubators. Journal of Business Venturing, 2 pp. 277-284.

[13] Mian, S. A. (1994). US university-sponsored technology incubators: an overview of management, policies and performance. Technovation. 14(8), pp. 515-528.

[14] Mian, S. A. (1997). Assessing the value-added contributions of university technology business incubators to tenant firms. Journal of Business Venturing, 12(4): pp. 251-285.

[15] O’Neal, T. (2005). Evolving a Successful University-Based Incubator: Lessons learned from the UCF Technology Incubator. Engineering Management Journal, 17(3), pp. 11-25.

[16] Osborne, J. W. and Banjanovic, E. S. (2016). An Exploratory Factor Analysis with SAS. SAS Instiotute Inc., Cary, NC, USA.

[17] Patton, M. Q. (ed.) (2002). Qualitative research \& evaluation methods, 3rd edition, SAGE Publications, Thousand Oaks.

[18] Sherman, H. and Chapell, D. S. (1998). Methodological Challenges in Evaluating Business Incubator Outcomes. Economic Development Quarterly, Vol 12 No. 4, pp. 313-321.

[19] Smilor, R. W. (1987). Commercializing Technology Through New Business Incubators. Research Management, 30(5), pp. 36-40.

[20] Soetanto, D. P. and Jack, S. L. (2011). Business incubators and the networks of technology-based firms. The Journal of Technology Transfer, 38(4), pp. 432-453.

[21] Spector, P. E. (1992). Summated rating scale construction: An introduction. Newbury Park, CA: SAGE Publications.

[22] Studdard, N. L. (2006). The effectiveness of entrepreneurial firm's knowledge acquisition from a business incubator. International Entrepreneurship Management Journal, 2(2), pp. 211-225.

[23] Tabachnick, B. J. and Fidell, L. S. (2001). Using Multivariate Statistics. $\left(4^{\text {th }}\right.$ Edition). Pearson Education Company.

[24] Vanderstraeten, J., Witteloostuijn, A. V., Matthyssens, P. and Andreassi, T. (2016). Being flexible through customization - The impact of incubator focus and customization strategies on incubatee survival and growth. Journal of Engineering and Technology Management, 41, pp. 45-64.

[25] Xiao, L. (2016). The graduation performance of technology business incubators in China's three tier cities: the role of incubator funding, technical support, and entrepreneurial mentoring. Springerlink.com. 